Original Research Paper

\title{
Bayesian Network Inference in Binary Logistic Regression: A Case Study of Salmonella sp Bacterial Contamination on Vannamei Shrimp
}

\author{
Pratnya Paramitha Oktaviana and Kartika Fithriasari \\ Department of Statistics, Institut Teknologi Sepuluh Nopember, Surabaya, Indonesia
}

\section{Article history}

Received: 28-11-2017

Revised: $14-12-2017$

Accepted: 20-12-2017

Corresponding Author: Pratnya Paramitha Oktaviana Department of Statistics, Institut Teknologi Sepuluh Nopember, Surabaya, Indonesia

Email: paramitha.oktaviana@gmail.com

\section{Introduction}

According to Hosmer and Lemeshow (2000), if there are $p$ predictor variables, indicated by the vector $x=$ $\left(x_{1}, x_{2}, \ldots, x_{\mathrm{p}}\right)$ and each of these variables is assumed at least interval scale, so the conditional probability could be indicated by $P(Y=1 \mid \mathrm{x})=\pi(\mathrm{x})$. The logistic regression model is:

$$
\pi(x)=\frac{\exp (g(x))}{1+\exp g((x))}
$$

Then the logit of that model could be written as:

$$
g(x)=\beta_{0}+\beta_{1} x_{1}+\ldots+\beta_{p} x_{p}
$$

If those $\mathrm{p}$ predictor variables are discrete or have nominal scale, the method of choice is to use dummy variables. If a nominal scaled variable has $m$ possible values, then $m-1$ dummy variables will be needed. Suppose that the $j^{\text {th }}$ predictor variable $x_{\mathrm{j}}$ has $m_{\mathrm{j}}$ levels. The $m_{\mathrm{j}}-1$ dummy variables will be indicated as $D_{\mathrm{jk}}$ and the coefficients for these dummy variables will be indicated as $B_{\mathrm{jk}}, k=1,2, \ldots, m_{\mathrm{j}}-1$. Then the logit of this case could be written as:

\begin{abstract}
Recently binary logistic regression has been used to identify four factors or predictor variables that supposedly influence the response variable, which is testing result of Salmonella $s p$ bacterial contamination on vannamei shrimp. Binary logistic regression analysis results that there Salmonella sp bacterial which is significantly affect the testing result of testing result of Salmonella $s p$ bacterial contamination on farmers hand swab and the subdistrict of vannamei shrimp ponds. Those significant paper proposes to study the statistical associations between the two significant predictor variables and the contamination of Salmonella $s p$ bacterial on vannamei shrimp and to build a numerical simulation of two inference. predictor variables parameters using bayesian network logit model of significant factors in bayesian network inference.
\end{abstract}

Keywords: Binary Logistic Regression, Bayesian Network, Salmonella sp Bacterial Contamination, Vannamei Shrimp, Parameters

$$
g(x)=\beta_{0}+\beta_{1} x_{1}+\ldots+\sum_{m=1}^{m_{j}-1} \beta_{j k} D_{j k}+\beta_{p} x_{p}
$$

Binary logistic regression is a logistic regression where the response variable used is dichotomous (or it is qualitative data which has binary or two categories) and the predictor variables are polichotomous (it could be qualitative or quantitative data).

Recently binary logistic regression has been used by the researchers to identify four factors or predictor variables $\left(X_{1}, X_{2}, X_{3}, X_{4}\right)$ that supposedly influence the response variable $(Y)$, which is the testing result of Salmonella $s p$ bacterial contamination on vannamei shrimp. This response variable $(Y)$ has two categories: $0=$ if testing result of Salmonella sp bacterial contamination on vannamei shrimp indicate that there is no Salmonella $s p$ on vannamei shrimp; $1=$ if testing result of Salmonella $s p$ bacterial contamination on vannamei shrimp indicate that there is Salmonella $s p$ on vannamei shrimp. While there are four predictor variables used: $X_{1}$ : The testing result of Salmonella $s p$ bacterial contamination on farmers hand swab (nominal scaled variable), $X_{2}$ : The subdistrict of vannamei shrimp ponds (nominal scaled variable), $X_{3}$ : The fish processing unit that supplaid by (nominal scaled variable) and $X_{4}$ : The pond area in hectare (ratio scaled variable). 


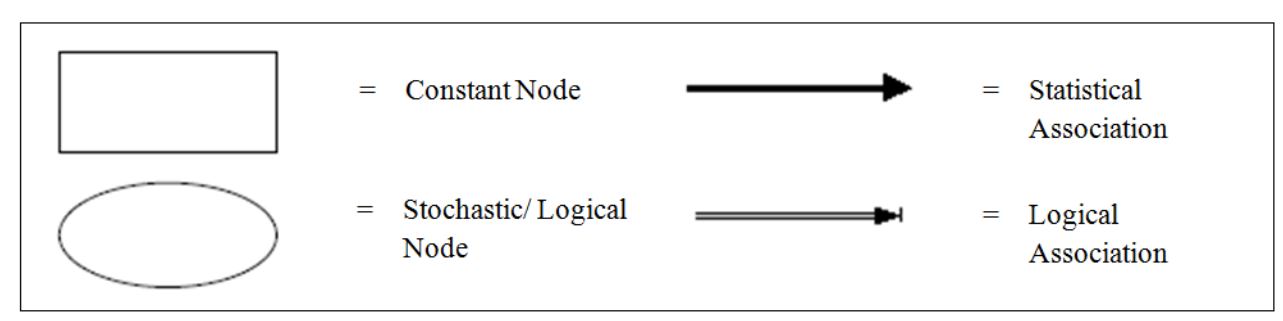

Fig. 1: The icon specification in DAG (Source: Liu, 2012)

Table 1: Link function in DAG

\begin{tabular}{ll}
\hline Link function & Formula \\
\hline Identity & $x_{i}$ \\
Logit & $\log i t\left(p_{i}\right)=\log \left[\frac{p_{i}}{1-p_{i}}\right]$ \\
Probit & Probit $\left(x_{\mathrm{i}}\right)$ \\
Cloglog & $\log \left(-\log \left(1-p_{\mathrm{i}}\right)\right)$ \\
Log & $\log \left(x_{\mathrm{i}}\right)$ \\
\hline
\end{tabular}

This method obtain that there are two significant predictor variables, i.e., $X_{1}$ and $X_{2}$. Those significant predictor variables have been modelled in binary logit model.

This paper proposes to study the statistical associations between the two significant predictor variables and the contamination of Salmonella $s p$ bacterial on vannamei shrimp and to build a numerical simulation of two significant predictor variables parameters using bayesian network inference. DAG is applied for modelling binary logit model of significant factors in bayesian network inference.

\section{Bayesian Network Inference}

Neapolitan (1989) in Stephenson (2000) explains that bayesian network is a specific type of graphical model, namely DAG. All of the edges in the graph are directed (the edges point in a particular direction) and there are no cycles (there is no way to start from any node and travel along a set of directed edges in the correct direction and arrive back at the starting node. The edges in bayesian network explain the joint distribution of all variables. The joint probability indicated by one set of edges can equally be indicated by another set.

Chen et al. (2015) explains that bayesian network is a set of variables, $X$ and $Y$, that present joint probability distribution, for $i=1,2, \ldots, n$ :

$$
P(X, Y)=\prod_{x_{i} \in X, Y} p\left(x_{i} \mid \operatorname{pr}\left(x_{i}\right)\right)
$$

DAG is used to illustrate all of the parameters and variables in thae model and connect them using the edges (Liu, 2012). The icon specification in DAG is presented in Fig. 1. There are three nodes in DAG as shown as in the Fig. 1:
1. Constant Node: It is used as the icon of random variable, for example: $x_{i} \sim N\left(\mu, \sigma^{2}\right)$

2. Stochastic Node: It is used as the icon of variable which is described by the other variables, generally to predict, for example: $\mu_{i}=\beta_{0}+\beta_{1} x_{i}$

3. Logical Node: It is used as the icon of observation value, hyper-parameters or constant, for example: $N=100, x_{i}$

Link function in DAG is presented in Table 1.

\section{Analysis and Result}

Binary logistic regression analysis results that there are two predictor variables which is significantly affect the testing result of Salmonella $s p$ bacterial contamination on vannamei shrimp (Y), those are the testing result of Salmonella $s p$ bacterial contamination on farmers hand swab $\left(X_{1}\right)$ and the subdistrict of vannamei shrimp ponds $\left(X_{2}\right)$. All of the research variables are shown in Table 2 .

This bayesian network analysis is perform by using WinBUGS software. The purpose of this analysis is to get all of the parameters estimation in binary logit model $\left(\hat{g}(x)=\left(\beta_{0}+\beta_{1} x_{1}+\beta_{2} x_{2}\right)\right)$, those are $\beta_{0}, \beta_{1}$ and $\beta_{2}$, where the parameter $\beta_{2}$ is written as $\beta_{2}(1), \beta_{2}(2), \beta_{2}(3)$ and $\beta_{2}(4)$ (according to: $X_{2}(1)$ (Subdistrict $\left.B\right), X_{2}(2)$ (Subdistrict $C), X_{2}(3)$ (Subdistrict $D$ ) and $X_{2}(4)$ (Subdistrict $E$ )).

The parameters estimation that is obtained by bayesian network is expected to show the statistical associations between $X_{1}$ and $X_{2}$ clearly. This bayesian network of binary logistic regression is also use the first reference category as same as the previous binary logistic regression. The DAG of this bayesian network is shown in Fig. 2. The model of DAG is denoted in Fig. 3.

In this bayesian network analysis, three markov chains iteration is used in simulation process. There are two conditions to continue bayesian analysis; those are the posterior distribution of parameters built should be stationary and the parameters should be convergence. Time series plot of history chains is used to check the stationary of posterior distribution. By looking Fig. 4, it obtains that the posterior distribution of parameters are stationary. Figure 5 is the Gelman Rubin statistics of parameters. It shows that the parameters are convergence. Therefore, bayesian network analysis could be continued. 
Pratnya Paramitha Oktaviana and Kartika Fithriasari / Journal of Mathematics and Statistics 2017, 13 (4): 306.311 DOI: 10.3844/jmssp.2017.306.311

Table 2: Research variables

\begin{tabular}{llll}
\hline Variable & Definition & Category & Scale \\
\hline$Y$ & The testing result of Salmonella $s p$ & $0:$ There is no Salmonella $s p$ & Nominal \\
& bacterial contamination on vannamei shrimp & $1:$ There is Salmonella $s p$ & Nominal \\
$X_{1}$ & The testing result of Salmonella $s p$ bacterial & $0:$ There is no Salmonella $s p$ & Nominal \\
& contamination on farmers hand swab & $1:$ There is Salmonella $s p$ & $0:$ Subdistrict A \\
$X_{2}$ & The subdistrict of vannamei shrimp ponds & $1:$ Subdistrict B & $2:$ Subdistrict C \\
& & $3:$ Subdistrict D & $4:$ Subdistrict E \\
& & & \\
& &
\end{tabular}

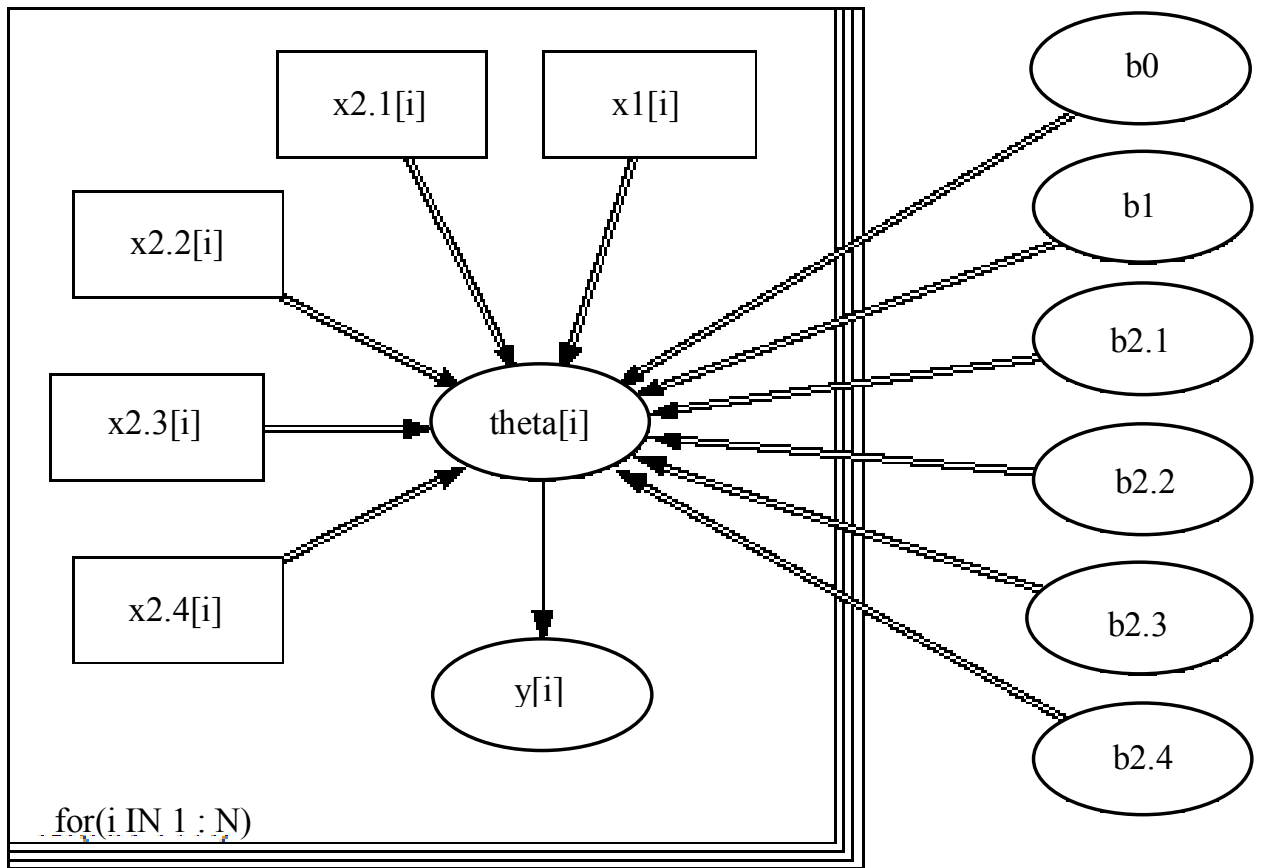

Fig. 2: The DAG for bayesian network of binary logistic regression

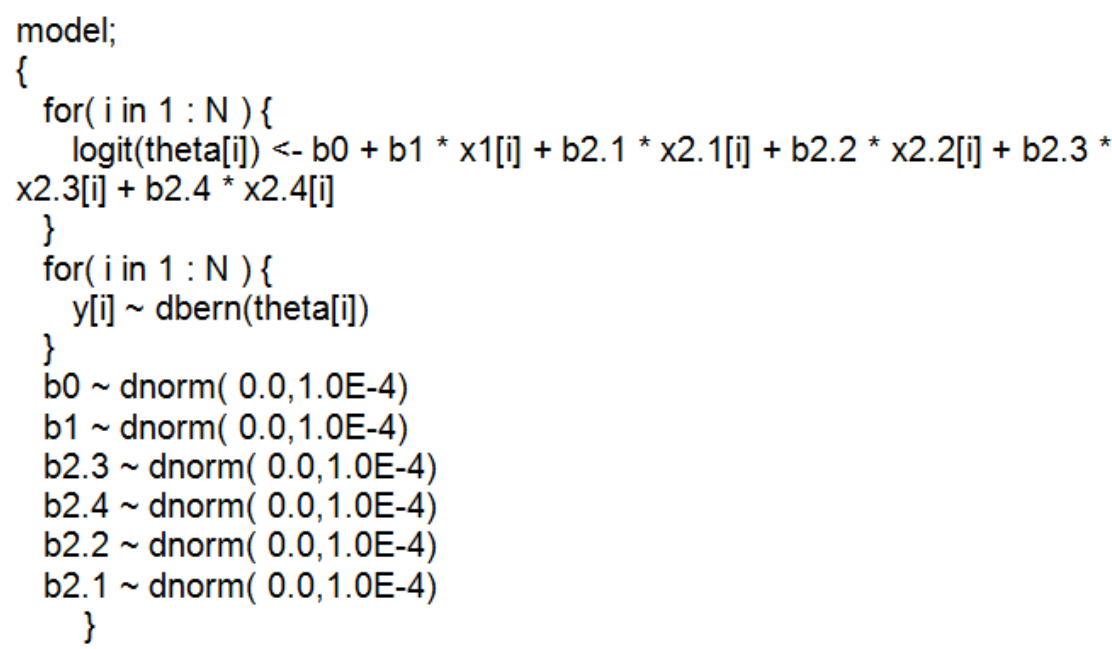

Fig. 3: The model of DAG 

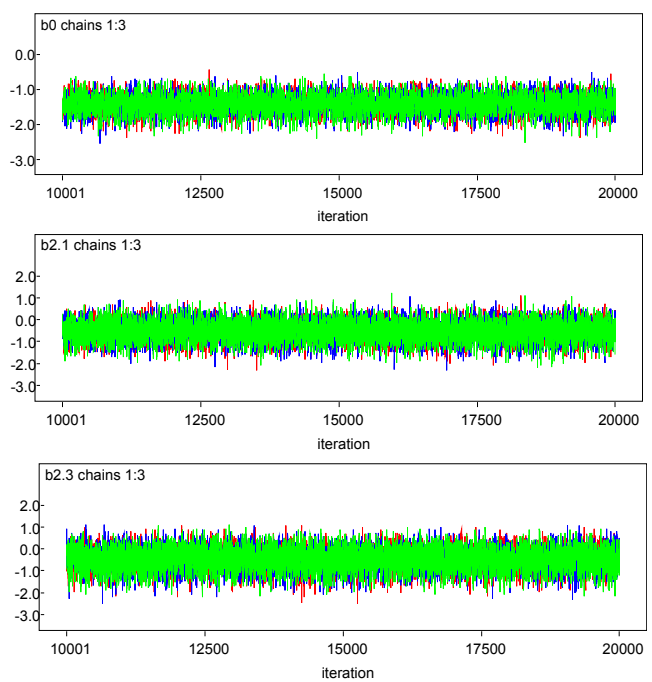
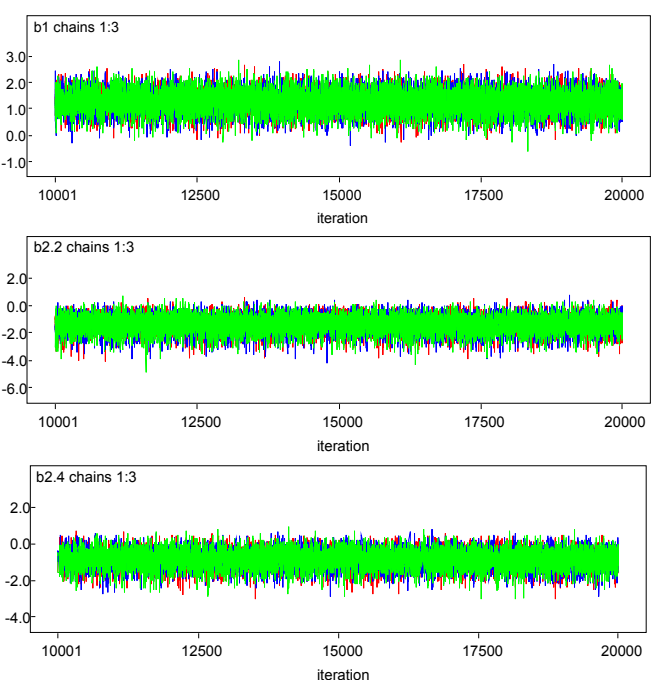

Fig. 4: Time series plot of history chain of parameters
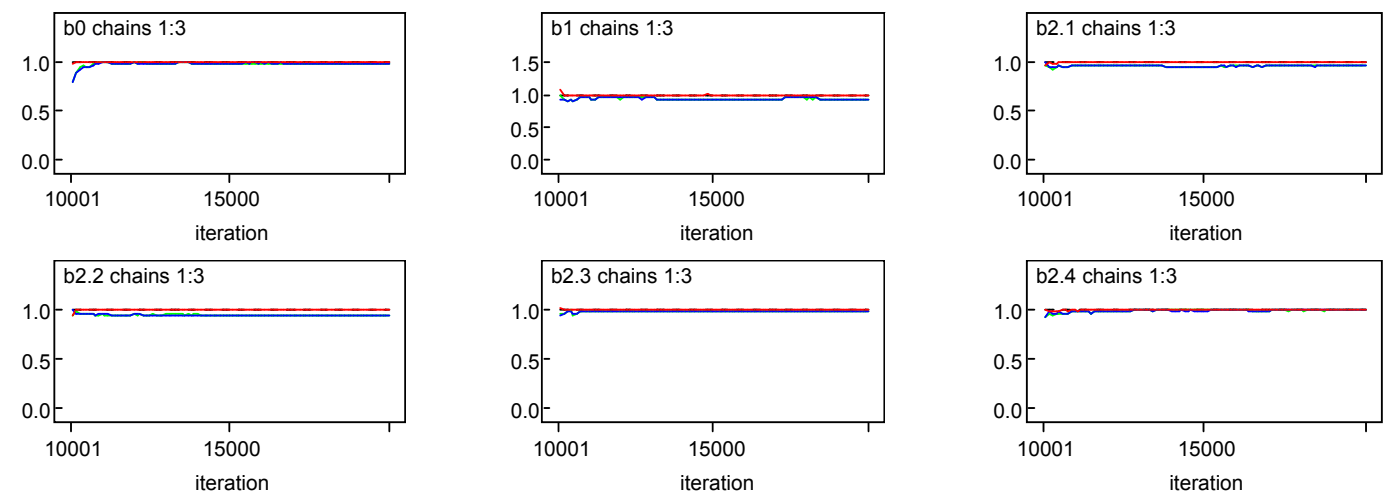

Fig. 5: Gelman rubin statistics of parameters

The results of parameters estimation using bayesian netwok are:

$\beta_{0}=-1.428, \beta_{1}=1.261, \beta_{2}(1)=-0.514, \beta_{2}(2)=-1.374$, $\beta_{2}(3)=-0.464$ and $\beta_{2}(4)=-0.855$

The binary logit model obtained is:

$$
\begin{aligned}
& \hat{g}(x)=-1.428+1.261 x_{1}-0.514 x_{2}(1)-1.374 x_{2}(2) \\
& -0.464 x_{2}(3)-0.855 x_{2}(4)
\end{aligned}
$$

The probability of presence or absence of Salmonella $s p$ in testing result of Salmonella $s p$ contamination on vannamei shrimp according to the testing result of Salmonella $s p$ bacterial contamination on farmers hand swab and the subdistrict of vannamei shrimp ponds with all of the possible combinationsis shown in Table 3 . Those probabilities is calculated by logit model of each combination, which are obtained by regress $Y$ and $X$ in all possibilities using DAG. The highest probability of the presence of Salmonella $s p$ in testing result on vannamei shrimp (0.350) is obtained if the vannamei shrimp is farmed in Subdistrict A and the testing result of Salmonella $s p$ contamination on farmer hand swab show that there is Salmonella $s p$; while the smallest probability of the presence of Salmonella $s p$ in testing result on vannamei shrimp (0.021) is obtained if the vannamei shrimp is farmed in Subdistrict $C$ and the testing result of Salmonella $s p$ contamination on farmer hand swab show that there is no Salmonella $s p$.

Therefore, the highest probability of the absence of Salmonella $s p$ in testing result on vannamei shrimp (0.979) is obtained if the vannamei shrimp is farmed in Subdistrict $C$ and the testing result of Salmonella $s p$ contamination on farmer hand swab show that there is no Salmonella sp; while the smallest probability of the absence of Salmonella $s p$ in testing result on vannamei shrimp (0.650) is obtained if the vannamei shrimp is farmed in Subdistrict $A$ and the testing result of Salmonella $s p$ contamination on farmer hand swab show that there is Salmonella $s p$. 
Table 3: The probability of presence or absence of Salmonella $s p$ in testing result of Salmonella sp contamination on vannamei shrip

\begin{tabular}{|c|c|c|c|}
\hline $\begin{array}{l}\text { The testing result of } \\
\text { Salmonella sp contamination } \\
\text { on farmer hand swab }\end{array}$ & $\begin{array}{l}\text { The subdistrict of } \\
\text { vannamei shrimp ponds }\end{array}$ & $\begin{array}{l}\text { The probability of the } \\
\text { absence of Salmonella } \\
s p \text { in testing result on } \\
\text { vannamei shrimp }\end{array}$ & $\begin{array}{l}\text { The probability of the } \\
\text { presence of Salmonella } \\
s p \text { in testing result on } \\
\text { vannamei shrimp }\end{array}$ \\
\hline \multirow{5}{*}{ There is no Salmonella $s p$} & Subdistrict A & 0.864 & 0.136 \\
\hline & Subdistrict B & 0.874 & 0.126 \\
\hline & Subdistrict C & 0.979 & 0.021 \\
\hline & Subdistrict D & 0.874 & 0.126 \\
\hline & Subdistrict E & 0.977 & 0.023 \\
\hline \multirow{5}{*}{ There is Salmonella $s p$} & Subdistrict A & 0.650 & 0.350 \\
\hline & Subdistrict B & 0.671 & 0.329 \\
\hline & Subdistrict C & 0.932 & 0.068 \\
\hline & Subdistrict D & 0.671 & 0.329 \\
\hline & Subdistrict E & 0.924 & 0.076 \\
\hline
\end{tabular}

\section{Conclusion}

The result of bayesian network analysis of binary logistic regression obtain the statistical associations between the significant predictor variables and the contamination of Salmonella $s p$ bacterial on vannamei shrimp which is show in probability as following:

- The probability of the presence of Salmonella $s p$ in testing result on vannamei shrimp obtained if the vannamei shrimp is farmed in Subdistrict A and the testing result of Salmonella $s p$ contamination on farmer hand swab show that there is Salmonella $s p$, is 0.350

- The probability of the presence of Salmonella $s p$ in testing result on vannamei shrimp obtained if the vannamei shrimp is farmed in Subdistrict B and the testing result of Salmonella $s p$ contamination on farmer hand swab show that there is Salmonella $s p$, is 0.329

- The probability of the presence of Salmonella $s p$ in testing result on vannamei shrimp obtained if the vannamei shrimp is farmed in Subdistrict $\mathrm{C}$ and the testing result of Salmonella $s p$ contamination on farmer hand swab show that there is Salmonella $s p$, is 0.068

- The probability of the presence of Salmonella $s p$ in testing result on vannamei shrimp obtained if the vannamei shrimp is farmed in Subdistrict D and the testing result of Salmonella $s p$ contamination on farmer hand swab show that there is Salmonella sp, is 0.329

- The probability of the presence of Salmonella $s p$ in testing result on vannamei shrimp obtained if the vannamei shrimp is farmed in Subdistrict E and the testing result of Salmonella $s p$ contamination on farmer hand swab show that there is Salmonella $s p$, is 0.076

- The probability of the absence of Salmonella $s p$ in testing result on vannamei shrimp obtained if the vannamei shrimp is farmed in Subdistrict A and the testing result of Salmonella sp contamination on farmer hand swab show that there is no Salmonella $s p$, is 0.136

- The probability of the absence of Salmonella $s p$ in testing result on vannamei shrimp obtained if the vannamei shrimp is farmed in Subdistrict B and the testing result of Salmonella $s p$ contamination on farmer hand swab show that there is no Salmonella $s p$, is 0.126

- The probability of the absence of Salmonella $s p$ in testing result on vannamei shrimp obtained if the vannamei shrimp is farmed in Subdistrict $C$ and the testing result of Salmonella sp contamination on farmer hand swab show that there is no Salmonella $s p$ is 0.021

- The probability of the absence of Salmonella $s p$ in testing result on vannamei shrimp obtained if the vannamei shrimp is farmed in Subdistrict D and the testing result of Salmonella $s p$ contamination on farmer hand swab show that there is no Salmonella $s p$, is 0.126

- The probability of the absence of Salmonella $s p$ in testing result on vannamei shrimp obtained if the vannamei shrimp is farmed in Subdistrict E and the testing result of Salmonella sp contamination on farmer hand swab show that there is no Salmonella $s p$, is 0.023

\section{Acknowledgment}

We are grateful to LPPM ITS who gives the chance to finish this research in part of the research for beginner (Penelitian Pemula) in Institut Teknologi Sepuluh Nopember, Surabaya, Indonesia.

\section{Author's Contributions}

Pratnya Paramitha Oktaviana: Participated in all experiments, coordinated the data-analysis and contributed to the writing of the manuscript.

Kartika Fithriasari: Guide the first author and contributed to the writing of the manuscript. 


\section{Ethics}

The authors confirm that this paper is original and approved the manuscript. There is no ethical issues involved.

\section{References}

Chen, C., G. Zhang, R. Tarefder, J. Ma and H. Wei et al., 2015. A multinomial logit model-bayesian network hybrid approach for driver injury severity analyses in rear-end crashes. Elsevier: Accident Anal. Prevent., 80: 76-88. DOI: 10.1016/j.aap.2015.03.036
Hosmer, D.W. and D.S. Lemeshow, 2000. Applied Logistic Regression. 2nd Edn, John Wiley and Sons, Inc., New York, ISBN-10: 0471356328, pp: 373.

Liu, Y., 2012. Doodlebugs application. Department of Statistics, University of Missouri, Columbia.

Stephenson, T.A., 2000. An introduction to bayesian betwork theory and usage. Research Report, Idiap Research Institute, Martigny-Valais, Switzerland. 